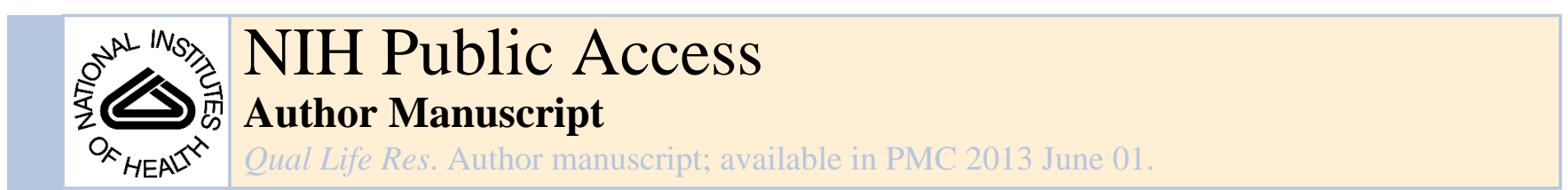

Published in final edited form as:

Qual Life Res. 2012 June ; 21(5): 813-825. doi:10.1007/s11136-011-9989-1.

\title{
Bodyweight, Gender, and Quality of Life: A Population-based Longitudinal Study
}

\author{
Rochelle E. Garner, $\mathrm{PhD}^{1}$, David H. Feeny, $\mathrm{PhD}^{2,3,4}$, Amanda Thompson, $\mathrm{MSc}^{5}$, Julie Bernier, \\ MSc $^{1}$, Bentson H. McFarland, MD, $\mathrm{PhD}^{6}$, Nathalie Huguet, $\mathrm{PhD}^{7}$, Mark S. Kaplan, $\mathrm{DrPH}^{7}$, \\ Heather Orpana, $\mathbf{P h D}^{5}$, Nancy A. Ross, $\mathbf{P h D}^{8}$, and Chris Blanchard, $\mathbf{P h D}^{9}$ \\ ${ }^{1}$ Health Analysis Division, Statistics Canada, Ottawa, Ontario, Canada \\ ${ }^{2}$ Kaiser Permanente Northwest Center for Health Research, Portland, Oregon, USA \\ ${ }^{3}$ Institute of Health Economics, University of Alberta, Edmonton, Canada \\ ${ }^{4}$ Health Utilities Incorporated, Dundas, Ontario, Canada \\ ${ }^{5}$ Department of Psychology, University of Ottawa, Ottawa, Ontario, Canada \\ ${ }^{6}$ Departments of Psychiatry and Public Health and Preventive Medicine, Oregon Health and Science \\ University, Portland, Oregon, USA \\ ${ }^{7}$ School of Community Health, Portland State University, Portland, Oregon, USA \\ ${ }^{8}$ Department of Geography, McGill University, Montreal, Quebec, Canada \\ ${ }^{9}$ Department of Medicine, Dalhousie University, Halifax, Nova Scotia, Canada
}

\section{Abstract}

Purpose-The objective of the paper is to describe trajectories of health-related quality of life (HRQL) associated with categories of body mass index (BMI): underweight, normal weight, overweight, obese class I, and obese classes II and III.

\begin{abstract}
Methods-Data come from the longitudinal Canadian National Population Health Survey. Analyses are based on data for 3864 males and 4745 females who were 40+ in 1998/99 and followed through 2006/07. HRQL was measured with the Health Utilities Index Mark 3. Multi-level growth modeling was used.
\end{abstract}

\begin{abstract}
Results-HRQL declined with age. For males, there was a large HRQL decrement for being underweight; trajectories for all other BMI categories were very similar. For females being underweight was associated with higher HRQL at younger ages but lower at older ages. Otherwise for females, HRQL was ordered from highest to lowest: normal, overweight, obese class I, and obese classes II and III.
\end{abstract}

Conclusions-Given that excess weight is a risk factor for mortality and the development of chronic conditions, the HRQL results for males are surprising. The HRQL results for females may reflect both the importance of body image on mental health and the health effects of excess weight.

Correspondence: David Feeny, The Center for Health Research, Kaiser Permanente Northwest, 3800 N. Interstate Avenue, Portland, OR 97227-1110 USA, Telephone: (503) 528-3937; FAX: (503) 335-2428, david.feeny @kpchr.org.

Conflict of Interest. It should be noted that David Feeny has a proprietary interest in Health Utilities Incorporated (HUInc.), Dundas, Ontario, Canada. HUInc. distributes copyrighted Health Utilities Index (HUI) materials and provides methodological advice on the use of HUI. It should be noted that HUInc. received no payment for the use of HUI in the study reported in this manuscript. None of the other authors declare any competing interests. 


\section{Keywords}

Body Mass Index; Health-Related Quality of Life; Obesity; Health Utilities Index; Trajectories

\section{Introduction}

Obesity is a major risk factor for a number of diseases and medical conditions, including type-2 diabetes, heart disease, stroke, hypertension, gout, urinary incontinence, sleep apnea, depression, colon cancer, breast cancer, ovarian cancer, kidney cancer, esophageal cancer, and pancreatic cancer [1-3]. In turn, each of these medical conditions is associated with decrements in health-related quality of life (HRQL). Further, obesity is associated with social stigma and reduced labor force participation and contributes to health disparities among racial and ethnic groups and across socioeconomic strata $[4,5]$.

A number of studies link obesity to higher rates of mortality [6-16]. The Prospective Studies Collaboration [17] summarized information from 57 studies on the relationship between body mass index (BMI) and mortality. Results pointed to an elevated mortality risk for body weights both below and above an apparent optimum range of 22.5 to $25 \mathrm{~kg} / \mathrm{m}^{2}$. Berrington and colleagues report similar results [18]. Using data from the United States (US) National Health and Nutrition Examination Survey (NHANES) I-III (1971-1975 to 1988-1994) with followup through 2000, Flegal and colleagues examined the relationship between BMI and all-cause mortality [8] and cause-specific mortality [9]. Results indicated that, relative to those in the normal weight range (BMI $\geq 18.5$ to $<25$ ), those classified as underweight $(\mathrm{BMI}<18.5$ ) were at a substantially higher risk of mortality; that those in obese classes II and III (BMI $\geq 35$ ) were at a substantially higher risk of mortality (except those $\geq 70$ years of age); that being overweight (BMI $\geq 25$ to $<30$ ) appeared to be protective (but not reaching statistical significance for all age groups); and that being classified by obese class I (BMI $\geq 30$ to $<35$ ) conferred no excess mortality risk. Using data from the Health and Retirement Survey and Americans' Changing Lives study Metha and Chang [19] and Lantz and colleagues [16] reported similar results.

Results from a study using Canadian data from the longitudinal National Population Health Survey (NPHS) were reported by Orpana and colleagues [20]. That study used data from 11,834 community-dwelling respondents (age 225 ) in 1994/95 with 12-year follow up through December 31, 2007 to examine the relationship between baseline BMI and subsequent mortality. For all-cause mortality, the relative risk (RR) of dying was significantly higher for those classified as underweight $(\mathrm{RR}=1.73)$ or as obese classes II and III $(\mathrm{RR}=1.36)$, whereas the risk of death was lower for those classified as overweight $(\mathrm{RR}=0.83$ ) when compared to those classified as normal weight. Being classified as obese class I did not appear to elevate the risk of mortality relative to those in the normal weight category.

While previous research has addressed the relative risks of body weight for a variety of medical conditions and mortality, this study explores the effects of BMI on HRQL. This study addresses the issue of whether being overweight or obese affects HRQL even if it does not appear to impose an excess mortality burden. Research in this area has mainly been cross sectional and has not examined how the relationship between BMI and HRQL change over time. In particular, this study examines the relationship between BMI category and the trajectory of HRQL for males and females.

The existing literature suggests that the relationship between BMI and HRQL differs between males and females and that being underweight or obese is associated with lower HRQL. For example, in a cross-sectional study based on data from Cycle 2 of the NPHS, Trakas et al. [21] found that the mean Health Utilities Index Mark 3 (HUI3) scores for obese class I and obese classes II and III for females were lower than scores for males. Using cross-sectional 
data from a 1995-1997 Canadian survey and using the Short-Form 36 (SF-36), Hopman et al. [22] found that being overweight or obese was associated with lower HRQL for women. For men being overweight was associated with higher HRQL while being obese was associated with lower HRQL. Using US data from the 2000 Medical Expenditure Panel Survey and EQ-5D, Muennig and colleagues [10] also found that the HRQL burden of being overweight and obese was higher for women than for men. Similarly, using data from the 1995 Australian National Health Survey and the SF-36, Kortt and Clarke [23] found that the HRQL burden of obesity was higher for women than for men. A more recent Australian study, using crosssectional analyses and SF-36, found a more substantial physical health burden than mental health burden for those who were obese relative to the non-obese [24]. Using data from a British health survey using the EQ-5D [25] to assess HRQL in cross-sectional analyses, Søltoft and colleagues reported that women had higher HRQL scores than men at BMI $<27.5$ but that men had higher scores at BMI levels greater than 27.5 [26]. Bentley and colleagues [27] report results from a 2005-06 population health survey of community-dwelling subjects in the US, the National Health Measurement Study, that included six major preference-based of HRQL. HRQL was highest for those in the normal weight range, followed by those in the overweight category, and lowest for those in the obese category; women who were obese had lower HRQL scores than men who were obese for each of the six measures. Strandberg and colleagues report on a cohort of high socioeconomic status Finish males born 1919=1934 and examine the relationship between weight gain based on recall of weight at age 25 and measured weight in 1974 [28]. Being in the highest quartile of weight gain was associated with a higher risk of mortality and lower HRQL as assessed by the RAND-36 [29]. Other studies also document the HRQL burden of obesity [30-36].

This study will extend previous research by examining the relationship between HRQL and BMI prospectively over a ten-year period. The results will provide insight into how BMI affects the course of HRQL over time. The relationship between BMI and HRQL will be assessed separately for males and females. Given the associations between being overweight or obese and the onset and severity of chronic conditions that negatively affect HRQL, one would expect that those in the normal weight category would experience the most favorable HRQL trajectories.

\section{Methods}

The data source for this study was the Canadian National Population Health Survey, a longitudinal survey designed to collect information on the health of the Canadian population along with related socio-demographic and lifestyle information [37]. The NPHS, conducted by Statistics Canada, began in 1994/95 and interviews have occurred every two years since. Due to changes in collection methods (primarily in-person in 1994/95, primarily by telephone since 1996/97) which may impact response patterns, in particular self-reported weight and height, [38, 39] the current study used data starting in the second cycle of the NPHS (1996/97) for the inception cohort of persons dwelling in the community at Cycle 1. By Cycle 2, 44 respondents who had been living in the community at Cycle 1 had been institutionalized. Data on BMI from cycles $2(1996 / 97)$ through $6(2004 / 05)$ were used in the analyses of trends in HRQL from cycles 3 (1998/99) through 7 (2006/07). The current study was limited to respondents in the longitudinal cohort who were alive and age 40 or older in 1998/99. Age 40 + was selected so that the HRQL effects of chronic conditions and/or low or high BMI would be more likely to be evident than would be the case if a younger population were included. The study was approved by the Institutional Review Board of Kaiser Permanente Northwest Region (NW-08DFeen-01). 


\section{Measures}

Health Utilities Index Mark 3-HRQL was assessed using HUI3, a generic preferencebased measure. HUI3 provides a measure of health status and HRQL by describing an individual's functional status in eight domains (attributes): vision, hearing, speech, ambulation, dexterity, emotion, cognition and pain. There are five or six levels for each attribute, ranging from no through severe disability. There is extensive evidence of the construct validity of the HUI3 in population health applications [40-48]. Overall HUI3 scores are derived from a multiplicative, multi-attribute utility function based on preference scores obtained from a random sample of the Canadian population [49] using the conventional scale in which dead = 0.00 and perfect health $=1.00$; scores below zero represent health states considered to be worse than dead. A difference (or change) of 0.03 or more in HUI3 score is considered to be clearly clinically meaningful $[40,50,51]$. This criterion is, in part, based on comparisons of mean scores for known groups in both cross-sectional and longitudinal studies. In population health applications, differences as small as 0.01 may be important [50].

Body weight could affect HUI3 directly or indirectly. For example, type-2 diabetes, a potential sequelae of obesity, might affect the ambulation (amputation), vision (retinopathy), dexterity (peripheral neuropathy), cognition, emotion (depression, anxiety), and pain and discomfort (peripheral neuropathy) attributes of HUI3 [44, 45]. Similarly osteoarthritis and joint problems associated with obesity might affect ambulation and pain and discomfort.

In the NPHS, HUI3 items were asked at every cycle. Individuals in the sample who died during the follow-up period were assigned a value of 0.00 for the first cycle following their death, and were not assigned an HUI3 value for subsequent cycles.

Body Mass Index-BMI is defined as an individual's weight in kilograms divided by their height in meters squared. In the NPHS, both height and weight are based on self-report. Women who were pregnant at the time of interview were not assigned a BMI score. Using standards set by the World Health Organization (http://apps.who.int/bmi/index.jsp?introPage=intro_3.html), continuous BMI scores were categorized into 5 groups: underweight $(\mathrm{BMI}<18.5)$; normal weight (BMI $\geq 18.5$ to $<25$ ); overweight (BMI $\geq 25$ to $<30$ ); obese class I (BMI $\geq 30$ to $<35$ ); and obese classes II and III (BMI 325 ). In all analyses, individuals of normal weight formed the reference group. To retain as many observations as possible, a missing BMI value at a particular cycle was denoted by a dichotomous indicator variable (which was also included as a predictor in the models).

Age-Age at interview was centered at 57, which was the mean age of sample respondents in $1998 / 99$ (mean $=57.2$, standard error $=0.13$ ). For individuals who died, their age at their final observation point was set to their age at death and their HUI3 score was set to 0.00. For respondents who died but for whom a date of death was not available, age at death was set as two years following their last interview.

\section{Analysis}

Lagged measures of BMI were used to predict HUI3 scores two years (one cycle) later. To account for the non-independent nature of repeated measures (HUI3 and BMI), multilevel growth curve modeling was utilized. This technique allowed for the examination of both intraand inter-individual differences in HUI3 over age. In these models, BMI categories were used as time-varying covariates, i.e., individuals could change BMI categories over time. Due to the lagging of BMI, a maximum of five observations points was possible, with the first observation of HUI3 occurring in 1998/99 (predicted by 1996/97 BMI). The majority of respondents (56.6\%) had five valid scores for HUI3: a further $16.8 \%$ had four observation points, $11.0 \%$ had three observations points, $10.0 \%$ had two observations points, and the final $5.7 \%$ had only 
one valid HUI3 score. No adjustments were made for multiple comparisons. All descriptive statistics were weighted using sampling weights and bootstrap weights provided by Statistics Canada to account for the complex survey design of the NPHS. Given that the objective of the paper was to describe the trajectories of HRQL by BMI category and not to explain those trajectories, potential confounders were not included in the models.

Previous work has shown that normative HUI3 trajectories differed for men and women [46], therefore models were run separately by gender. A two-level model was structured with time (level 1) being nested within individuals (level 2). HUI3 was modeled over age (centered at 57), and linear, quadratic and cubic rates of change in HUI3 were examined for statistical significance and improvement to model fit (as measured by change in -2 log likelihood and the Bayesian Information Criterion). In models for both men and women, a cubic pattern was found to best fit the data (data not shown), capturing the non-linear association between age and HRQL.

Intercept and slope parameters were examined for random variation. In the model for men, estimates for the intercept, linear rate of change and quadratic rate of change were found to vary significantly between individuals; models would not converge when examining random variation in cubic rates of change, therefore this estimate was fixed. In the model for women, convergence problems required that estimates for both quadratic and cubic rates of change be fixed.

To examine the association between BMI category and HUI3 over time, dummy variables for BMI categories, including missing BMI values, were included in the models, with normal weight category serving as the reference group. Interactions between BMI category indicators and slope parameters were used to examine the effects of BMI on change in HUI3 scores as individuals aged. All BMI-related effects were fixed (i.e. were not allowed to vary randomly between individuals).

Models were weighted using the sampling weights to adjust for the complex survey design of the NPHS and applied to the second level of the model (level of the individual). Variance estimates were not adjusted for the complex sampling design of the survey.

Transformation of the outcome measure-Due to the highly skewed nature of the distribution of HUI3 scores, transformation of the outcome measure was necessary to achieve normally distributed residuals. The arcsine transformation was used. Further detail is provided in the Appendix and in Bernier et al.[52]

\section{Results}

\section{Description of the sample (Table 1)}

There were 8609 respondents in the longitudinal cohort who were alive and age 40 or older in 1998/99. Of these individuals, 1363 (15.8\%) died over the course of follow-up and 406 (4.7\%) were institutionalized. Some 2461 subjects were lost to follow-up during Cycles 3 (1998/99) through 7 (2006/07).

\section{Body mass index categories across age}

The first observation for BMI occurred in 1996/97. At that cycle, more males (50.3\%) than females were overweight (33.1\%) and more females (49.1\%) than males (33.5\%) were in the normal weight category (Table 1 ).

The proportion of respondents in each age group and BMI category by gender is presented in Table 2. As respondents age their responses are reported in older age intervals as they change 
from one age category to another. The distribution of BMI categories varied greatly across age groups (Table 2). As men aged, the proportion of those in the normal weight category increased, while the proportion of men in the underweight category was significantly greater for men in their eighties than it was for men aged 55 to 59. The proportion of women in various BMI categories did not seem to vary across the age span, except at the younger and older ends of the age spectrum (Table 2). More than half of subjects (55.9\% for males and $53.6 \%$ for females) remained in their initial BMI category throughout the follow up period.

\section{Growth curve models: Men}

Compared to the model containing only age-related factors (Table 3, Model A), the addition of BMI indicators (Table 3, Model B) resulted in significantly improved model fit. Underweight men had significantly lower HUI3 values at baseline compared to normal weight men, whereas men who were overweight had significantly higher HUI3 scores than those in the normal weight range; obese men, whether class I or II/III, had HUI3 scores similar to those of normal weight men at baseline (Table 3, Model B). BMI categories had no effect on change in HUI3 over time; in other words there were no significant interactions between BMI category and age (Table 3, Model C).

To illustrate the results, estimates from the final model (Table 3, Model D), in which nonsignificant BMI category indicators were removed, were back-transformed and plotted in Figure 1A. Although the figures depict a stable BMI category over time, if a subject changed BMI category, he would in effect switch from the trajectory for his initial BMI category to the trajectory for his new BMI category. The figures illustrate the results of level 1 of the multilevel model. Men across all BMI categories shared similar rates of change in HUI3 over time (Figure 1A). The significant decrement in HUI3 experienced by underweight men was maintained across the age range examined. Although being overweight was associated at baseline with statistically significantly higher HUI3 scores (Table 3, Model D), the gap between HUI3 for overweight men and those with normal weight did not meet the threshold for clinical importance. In Figure 1A, because the trajectories for normal weight males and the obese were virtually identical, the trajectories were combined. Predicted HUI3 scores among overweight men were always within \pm 0.03 units of predicted HUI3 scores among normal weight men (Figure 2A). Conversely, underweight men showed significantly poorer HRQL at every age. Although the proportion of underweight men is low at all ages, the proportion of men who are classified as underweight does increase with age. Therefore, this significant decline in HRQL is experienced by a larger proportion of men at older ages compared to younger ages.

\section{Growth curve models: Women}

Starting with the model for women containing only age-related factors (Table 4, Model A), the addition of BMI category indicators resulted in significant improvement in model fit and revealed significant effects of all BMI categories on baseline (age 57) HUI3 scores (Table 4, Model B). Compared to normal weight women, underweight, overweight, and obese (class I or classes II/III) women had significantly lower HUI3 scores at age 57 (Table 4, Model B). Unlike the model for men, there were several significant interactions between BMI categories and rates of change in HUI3 over time (Table 4, Model C), indicating that the effect of BMI on HRQL differed by age. After omitting non-significant interaction and baseline terms for the final model (Table 4, Model D), it was found that all BMI categories had unique HUI3 trajectories across age.

Although underweight women had similar HUI3 scores to normal weight women at age 57, their HRQL decreased much more steeply at older ages (Figure 1B). Starting at age 62 and increasing thereafter, the difference in HUI3 scores between normal weight and underweight women exceeded the clinically important threshold of 0.03 units (Figure 2B). Conversely, the 
difference in HUI3 scores between overweight and normal weight women, although statistically significant, never exceeded 0.03 units between the ages of 40 and 80, indicating that overweight and normal weight women shared clinically similar HRQL trajectories. Obese class I was associated with statistically significant and clinically important lower HRQL for women starting in their mid-sixties. Women in obese classes II and III had significantly and clinically important lower HRQL throughout most of the period of investigation. The difference in HUI3 scores from those of normal weight was greatest for women in their late fifties through early sixties, but was less pronounced for younger or older women.

Visual inspection of Figures 1 and 2 and results reported in Tables 3 and 4 suggests that the trajectories of HRQL for males and females differ. The lack of overlap in the confidence intervals for the coefficients for the linear rate of change over time in HUI3 scores for males and females (data not shown) is consistent with the observation that there are fundamental differences in the trajectories by gender.

\section{Discussion}

Baseline values and longitudinal trajectories of HRQL of Canadians are influenced by bodyweight, but these effects are highly gender specific. For men, there is a substantial HRQL burden associated with being underweight and that decrement persists over time. However, being overweight is associated with higher HRQL at age 57 than being in the normal weight category. Over time, those in the normal weight, overweight, and the obese categories experienced very similar age-related declines in HRQL. Similar results are reported by others $[10,22,23]$. This should be considered in the context that the prevalence of overweight, obese class I, and obese classes II and III declines with age and the prevalence of the normal weight category increases with age (Table 2). Further, the results for males may reflect that males who remain fit and retain muscle mass and who are technically overweight, may be more likely to survive and experience high HRQL.

The story is much more complicated for women. Being underweight is associated with modestly higher HRQL at younger ages, but a substantial HRQL decrement at older ages. The trajectory for underweight women may reflect a social advantage of thinness at younger ages that becomes a physical disadvantage with advancing age. Relative to the normal weight category, from the mid-40s on, obese classes II and III are associated with substantially lower HRQL. Leaving the underweight aside, from the mid-40s on, the ordering of HRQL conforms to what one might expect: those in the normal weight category experienced the highest HRQL, followed by the overweight, who were in turn followed by the obese class I and obese classes II and III. Similar findings are reported elsewhere [22].

Given that being obese is a risk factor for the development of a number of chronic conditions with well documented HRQL burdens, the lack of a HRQL decrement for obese males is perhaps surprising. For instance, type-2 diabetes is associated with a lower HRQL, controlling for age, income, education, other chronic conditions, and other important determinants of health [44, 45, 53, 54]. Similarly, stroke is associated with substantial HRQL deficits [51], as is sleep apnea [55] and coronary heart disease [48]. Further, Zajacova and colleagues present evidence from NHANES 2005-2006 and 2007-2008 surveys indicating a monotonic relationship between biomarkers of inflammation (C-reactive protein), metabolic function (hemoglobin $\mathrm{A}_{1 \mathrm{c}}$ ), and cardiovascular risk (high density lipoprotein cholesterol) and BMI for both genders [56]. Similarly, Visser and colleagues report that c-reactive protein levels among those who are overweight are higher than among those in the normal weight range and higher still in the obese [57]. The duration of the follow-up in the current study was 10 years. It may be that chronic conditions take more than 10 years to become apparent. Similarly, even if chronic conditions develop, there may be little or no initial HRQL burden. It may take 
additional time for those burdens to become manifest. Further, these results may reflect survivor bias in that those most seriously affected may have been institutionalized or died. However, the NPHS follows subjects into long-term care facilities and those who died are retained in the analyses for one cycle with their HUI3 score set at zero, the score for dead.

Another possible explanation for the lack of HRQL decrement in males for being obese may be the vigilance of the healthcare system in screening for, identifying, and intervening to modify risk factors. This conjecture is congruent with results reported by Flegal et al. [8] that obese class I was associated with an elevated risk of mortality when using data from the NHANES I (1971-75) but was not associated with an elevated risk of mortality when using data from NHANES II (1976-80) and III (1988-94).

The relationship between BMI and HRQL for women is much more complicated than the relationship for men. Given the importance of body image in cultural norms for females, underweight women may enjoy a HRQL "premium" at younger ages" [4, 58]. Further, it is plausible that the stigma attached to being overweight or obese is much more substantial for women than for men, accounting for the observation that the HRQL decrement is higher with each BMI category above normal weight. To assess the plausibility of stigma as an explanation for gender differences, the mean HUI3 emotion scores for males and females were examined, excluding the underweight. The mean HUI3 emotion scores for females aged 50 to 65 were highest for those in the normal weight category, followed by the overweight, obese class I, and obese classes II and III. In contrast for males, the mean was highest for the overweight, the same for normal and obese I, and lowest for obese classes II and III. These results are consistent with the stigma interpretation, but the differences in means were not large so the results are not driven solely by stigma.

It is important to compare the effects of BMI on mortality to the effects on morbidity (HRQL). In an earlier analysis of the relationship between BMI and mortality, [20] being underweight was associated with a substantially elevated risk of mortality, even when deaths in the first four years of follow-up were excluded. These results for mortality resonate with the HRQL decrements associated with being underweight for males. For younger females, however, being underweight is associated with higher HRQL. Yet for females in their 50s and older, being underweight is associated with a higher HRQL burden that increases with age. In Orpana and colleagues [20] being overweight was protective with respect to mortality risk. Overweight males also enjoyed higher HRQL than those in the normal weight category. This was not the case for overweight females, although for both males and females the difference in HRQL between the overweight and the normal weight was relatively small. In Orpana and colleagues [20], obese class I was associated with approximately the same risk of mortality as being in the normal weight category. With respect to HRQL, obese males experienced approximately the same HRQL as those in the normal weight class. For females, however, obese women, both class I and especially classes II and III, experienced substantial HRQL deficits relative to their normal weight peers. Mortality risks for women in classes II and III were substantially higher than the risks for normal weight women. In summary, with the exception of younger women, there is congruence between the mortality risk and HRQL burdens for the underweight. For women, obese classes II and III are both associated with reduced HRQL and a higher mortality risk. However while males in obese classes II and III are at a higher risk of mortality, their HRQL appears to be largely unaffected.

There are several limitations to the study. First, because the estimates of variance were not corrected for the clustered design of the survey, the levels of statistical significance may be slightly overstated. However, in a number of previous analyses of longitudinal data from the NPHS, the adjustment for sample design often had little quantitative impact on the results. Second, weight and height were based on self-report. In analyses of this data examining the 
relationship between BMI and mortality, using a correction factor [59] had minimal effects on the results [20]. It should be noted, however, that the correction factor was estimated in a study in which the interviews were conducted in person and thus perhaps the discrepancy between self-report and measured height and weight might be smaller than in the NPHS (for the period analyzed here) for which data were collected in telephone interviews. Third, BMI does not distinguish between muscle and fat. Other measures such as waist circumference or the ratio of waist to hip circumference provide more valid evidence on body composition[60] but these variables were not available in the NPHS. Nonetheless, results from the 2007 - 2009 Canada Health Measures Survey that included measured height, weight, waist circumference, hip circumference, and five skin fold measurements indicate that BMI is systematically associated with body fat [61]. Fourth, as noted above, the 10-year period of follow-up may be insufficient for the HRQL burdens associated with BMI to emerge. Fifth, there was sample attrition from the NPHS. If those who experienced the HRQL burdens of excess weight were over-

represented among the subjects lost to follow-up, the results would underestimate the effects of excess weight on HRQL. Baseline characteristics of those lost to follow-up, however, did not differ substantially from the characteristics of the entire sample. A comparison (data not shown) of the baseline (1996/97) characteristics of those lost to follow-up to the entire sample indicates that those lost-to-follow-up were slightly more likely to be male, a bit older, less healthy, and slightly more likely to be in the underweight or normal weight categories and less likely to be in the overweight or obese classes II and III categories. Attrition bias is unlikely to have influenced the results. Sixth, it is possible that unhealthy obese subjects were under represented in the baseline cohort. Such an under representation could bias the results. Nonetheless there is substantial evidence that the inception cohort for the NPHS was a representative sample of the community-dwelling Canadian population [37, 62]. Seventh, generic measures of HRQL such as HUI3 are probably less sensitive than specific targeted measures to some of the HRQL effects of excess weight. Obesity-specific health-related quality of life instruments such as the Moorehead-Ardelt Quality of Life Questionnaire [63] and Impact of Weight on Quality of Life (IWQOL) instrument [64] focus on a variety of domains including self-esteem, physical well-being, social relationships, work, sexuality, mobility, activities of daily living, and comfort with food. HUI3 may quite adequately capture the effects on physical well-being and mobility and some of these psycho-social effects but is probably less sensitive than specific measures to domains such as self-esteem, sexuality, social relationships, and comfort with food. Unfortunately, the NPHS did not include any weight specific measures. As noted above, however, there is substantial evidence on the construct validity of HUI3 in studies of type-2 diabetes, sleep apnea, cardiovascular disease, arthritis, mental health, and other health problems and chronic conditions associated with obesity. Further, Pinto and colleagues [30] in a study of overweight and obese women with urinary incontinence that included several generic measures, the Quality of Well Being scale, the Short Form-36 (and Short Form-6D), and HUI3, concluded that "the association between BMI and HUI3 in the current study suggests that HUI3 is sensitive to the health effects of obesity and thus may be a useful tool to measure HRQL in studies of obesity and weight loss." Nonetheless, given that HUI3 is a generic measure, the HRQL burden associated with excess weight may have been underestimated. Lastly, this cohort of Canadians did not grow up with the so-called epidemic of childhood obesity and because we do not know the duration of exposure to excess or underweight in childhood and adolescence of this group, the relationship between BMI and HRQL presented here may not hold for future cohorts and may underestimate the effects of lifetime exposure.

\section{Conclusions}

The HRQL of Canadians declines as they age. These results highlight a substantial additional HRQL penalty associated with the extremes in weight, the underweight for both males and females and obesity classes II and III for females; results that are congruent with the relative risk of mortality. For males, being overweight or even obese did not seem to be associated with 
lower HRQL. In contrast, for females it appears that there was an important HRQL burden associated with being overweight or obese and this burden increases as BMI diverges more from the normal weight category. The effects of bodyweight on HRQL clearly differ by gender and while we have hinted here that some of these differences may reflect a higher social penalty paid by women, these results warrant further exploration. In future studies it may be important to examine patterns in the emergence of chronic conditions and trends in psychological health in cohorts of males and females. In the meantime perhaps clinical and public health policy should focus on the extremes.

\section{Acknowledgments}

The authors acknowledge the contributions of Jillian Oderkirk and Kathy Easter to the research reported here. The authors also acknowledge the constructive comments and suggestions made by three anonymous reviewers. This study was supported by National Institutes of Health grants AG027129 from the National Institute on Aging and DK080277 from the National Institute of Diabetes and Digestive and Kidney Diseases. The funding source had no involvement in the collection, analysis, and interpretation of the data, in the writing of the paper, and did not review or approve of the manuscript prior to its submission for publication. The work reported here was previously presented at the Canadian Institute for Health Information and Statistics Canada Data Users Conference 2010 in Ottawa, September 20-21, 2010; Department of Clinical Epidemiology and Biostatistics CE \& B Rounds, McMaster University, Hamilton, Ontario, September 22, 2010; and $17^{\text {th }}$ Annual Meeting of the International Society for Quality of Life Research, London, October 27-30, 2010. The authors are grateful for the constructive comments received at those three presentations

\section{List of Abbreviations}

$\begin{array}{ll}\text { BMI } & \text { Body Mass Index } \\ \text { HRQL } & \text { Health-Related Quality of Life } \\ \text { HUI3 } & \text { Health Utilities Index Mark 3 } \\ \text { NHANES } & \text { National Health and Nutrition Examination Survey } \\ \text { NPHS } & \text { National Population Health Survey } \\ \text { RR } & \text { Relative Risk } \\ \text { SF-36 } & \text { Short-Form } 36 \\ \text { US } & \text { United States }\end{array}$

\section{References}

1. Haslam DW, James WP. Obesity. Lancet. 2005; 366(9492):1197-1209. [PubMed: 16198769]

2. Wei M, Kampert JB, Barlow CE, Nichaman MZ, Gibbons LW, Paffenbarger RS Jr, et al. Relationship between low cardiorespiratory fitness and mortality in normal-weight, overweight, and obese men. JAMA. 1999; 282(16):1547-1553. [PubMed: 10546694]

3. Samanic C, Chow WH, Gridley G, Jarvholm B, Fraumeni JF Jr. Relation of body mass index to cancer risk in 362,552 Swedish men. Cancer Causes Control. 2006; 17(7):901-909. [PubMed: 16841257]

4. Puhl RM, Heuer CA. The stigma of obesity: a review and update. Obesity (Silver Spring). 2009; 17 (5):941-964. [PubMed: 19165161]

5. Klarenbach S, Padwal R, Chuck A, Jacobs P. Population-based analysis of obesity and workforce participation. Obesity (Silver Spring). 2006; 14(5):920-927. [PubMed: 16855202]

6. Olshansky SJ, Passaro DJ, Hershow RC, Layden J, Carnes BA, Brody J, et al. A potential decline in life expectancy in the United States in the 21st century. N Engl J Med. 2005; 352(11):1138-1145. [PubMed: 15784668]

7. Flegal KM, Williamson DF, Pamuk ER, Rosenberg HM. Estimating deaths attributable to obesity in the United States. Am J Public Health. 2004; 94(9):1486-1489. [PubMed: 15333299]

8. Flegal KM, Graubard BI, Williamson DF, Gail MH. Excess deaths associated with underweight, overweight, and obesity. JAMA. 2005; 293(15):1861-1867. [PubMed: 15840860] 
9. Flegal KM, Graubard BI, Williamson DF, Gail MH. Cause-specific excess deaths associated with underweight, overweight, and obesity. The Journal of the American Medical Association. 2007; 298 (17):2028-2037.

10. Muennig P, Lubetkin E, Jia H, Franks P. Gender and the burden of disease attributable to obesity. Am J Public Health. 2006; 96(9):1662-1668. [PubMed: 16873748]

11. Adams KF, Schatzkin A, Harris TB, Kipnis V, Mouw T, Ballard-Barbash R, et al. Overweight, obesity, and mortality in a large prospective cohort of persons 50 to 71 years old. N Engl J Med. 2006; 355(8):763-778. [PubMed: 16926275]

12. Yang W, Kelly T, He J. Genetic epidemiology of obesity. Epidemiol Rev. 2007; 29:49-61. [PubMed: 17566051]

13. Bender R, Zeeb H, Schwarz M, Jockel KH, Berger M. Causes of death in obesity: relevant increase in cardiovascular but not in all-cancer mortality. Journal of Clinical Epidemiology. 2006; 59(10): 1064-1071. [PubMed: 16980146]

14. Willcox BJ, He Q, Chen R, Yano K, Masaki KH, Grove JS, et al. Midlife risk factors and healthy survival in men. JAMA. 2006; 296(19):2343-2350. [PubMed: 17105797]

15. Freedman DM, Sigurdson AJ, Rajaraman P, Doody MM, Linet MS, Ron E. The mortality risk of smoking and obesity combined. Am J Prev Med. 2006; 31(5):355-362. [PubMed: 17046405]

16. Lantz PM, Golberstein E, House JS, Morenoff J. Socioeconomic and behavioral risk factors for mortality in a national 19-year prospective study of U.S. adults. Soc Sci Med. 2010; 70(10):15581566. [PubMed: 20226579]

17. Whitlock G, Lewington S, Sherliker P, Clarke R, Emberson J, Halsey J, et al. Body-mass index and cause-specific mortality in 900000 adults: collaborative analyses of 57 prospective studies. Lancet. 2009; 373(9669):1083-1096. [PubMed: 19299006]

18. Berrington de Gonzalez A, Hartge P, Cerhan JR, Flint AJ, Hannan L, MacInnis RJ, et al. Body-mass index and mortality among 1.46 million white adults. The New England Journal of Medicine. 2010; 363(23):2211-2219. [PubMed: 21121834]

19. Mehta NK, Chang VW. Mortality attributable to obesity among middle-aged adults in the United States. Demography. 2009; 46(4):851-872. [PubMed: 20084832]

20. Orpana HM, Berthelot JM, Kaplan MS, Feeny DH, McFarland B, Ross NA. BMI and mortality: results from a national longitudinal study of Canadian adults. Obesity (Silver Spring). 2010; 18(1): 214-218. [PubMed: 19543208]

21. Trakas K, Oh PI, Singh S, Risebrough N, Shear NH. The health status of obese individuals in Canada. Int J Obes Relat Metab Disord. 2001; 25(5):662-668. [PubMed: 11360148]

22. Hopman WM, Berger C, Joseph L, Barr SI, Gao Y, Prior JC, et al. The association between body mass index and health-related quality of life: data from CaMos, a stratified population study. Qual Life Res. 2007; 16(10):1595-1603. [PubMed: 17957495]

23. Kortt MA, Clarke PM. Estimating utility values for health states of overweight and obese individuals using the SF-36. Quality of Life Research. 2005; 14(10):2177-2185. [PubMed: 16328898]

24. Renzaho A, Wooden M, Houng B. Associations between body mass index and health-related quality of life among Australian adults. Qual Life Res. 2010; 19(4):515-520. [PubMed: 20182918]

25. Rabin R, de Charro F. EQ-5D: A measure of health status from the EuroQol Group. Ann Med. 2001; 33(5):337-343. [PubMed: 11491192]

26. Soltoft F, Hammer M, Kragh N. The association of body mass index and health-related quality of life in the general population: data from the 2003 Health Survey of England. Qual Life Res. 2009; 18 (10):1293-1299. [PubMed: 19813103]

27. Bentley TGK, Palta M, Paulsen A, Cherepanov D, Dunham NC, Feeny D, et al. Race and gender associations between obesity and nine health related Quality of Life measures. Quality of Life Research. 2011; 5(20):655-674.

28. Strandberg TE, Strandberg A, Salomaa VV, Pitkala K, Miettinen TA. Impact of midlife weight change on mortality and quality of life in old age. Prospective cohort study. International Journal of Obesity and Related Metabolic Disorders. 2003; 27(8):950-954. [PubMed: 12861236]

29. Hays RD, Morales LS. The RAND-36 measure of health-related quality of life. Ann Med. 2001; 33 (5):350-357. [PubMed: 11491194] 
30. Pinto AM, Kuppermann M, Nakagawa S, Vittinghoff E, Wing RR, Kusek JW, et al. Comparison and correlates of three preference-based health-related quality-of-life measures among overweight and obese women with urinary incontinence. Qual Life Res. 2011

31. Sullivan PW, Ghushchyan VH, Ben-Joseph R. The impact of obesity on diabetes, hyperlipidemia and hypertension in the United States. Quality of Life Research. 2008; 17(8):1063-1071. [PubMed: 18777200]

32. Serrano-Aguilar P, Munoz-Navarro SR, Ramallo-Farina Y, Trujillo-Martin MM. Obesity and health related quality of life in the general adult population of the Canary Islands. Quality of Life Research. 2009; 18(2):171-177. [PubMed: 19067234]

33. Sach TH, Barton GR, Doherty M, Muir KR, Jenkinson C, Avery AJ. The relationship between body mass index and health-related quality of life: comparing the EQ-5D, EuroQol VAS and SF-6D. Int J Obes (Lond). 2007; 31(1):189-196. [PubMed: 16682976]

34. Jia H, Lubetkin EI. The impact of obesity on health-related quality-of-life in the general adult US population. J Public Health (Oxf). 2005; 27(2):156-164. [PubMed: 15820993]

35. Minet KJ, Morris S. Socioeconomic variation in the impact of obesity on health-related quality of life. Soc Sci Med. 2010; 71(10):1864-1871. [PubMed: 20932623]

36. Dixon JB. The effect of obesity on health outcomes. Mol Cell Endocrinol. 2010; 316(2):104-108. [PubMed: 19628019]

37. Tambay JL, Catlin G. Sample design of the national population health survey. Health Rep. 1995; 7 (1):29-42. [PubMed: 7578995]

38. Ezzati M, Martin H, Skjold S, Vander HS, Murray CJ. Trends in national and state-level obesity in the USA after correction for self-report bias: analysis of health surveys. J R Soc Med. 2006; 99(5): 250-257. [PubMed: 16672759]

39. St-Pierre, M.; Beland, Y. Mode effects in the Canadian community health survey: A comparison of CAPI and CATI, Proceedings of the American Statistical Association. 2004 Proceedings of the American Statistical Association Meeting, Survey Research Methods; Alexandria, VA: American Statistical Association; 2004.

40. Horsman J, Furlong W, Feeny D, Torrance G. The Health Utilities Index (HUIß): concepts, measurement properties and applications. Health and Quality of Life Outcomes. 2003; 1(1):54. [PubMed: 14613568]

41. Asakawa K, Rolfson D, Senthilselvan A, Feeny D, Johnson JA. Health Utilities Index Mark 3 showed valid in Alzheimer Disease, arthritis, and cataracts. J Clin Epidemiol. 2008; 61(7):733-739. [PubMed: 18359192]

42. Feeny D, Huguet N, McFarland BH, Kaplan MS. The construct validity of the Health Utilities Index Mark 3 in assessing mental health in population health surveys. Qual Life Res. 2009; 18(4):519-526. [PubMed: 19277898]

43. Kaplan MS, Berthelot JM, Feeny DH, McFarland B, Kahn S. The predictive validity of two measures of health-related quality of life: mortality in a longitudinal population-based study. Qual Life Res. 2007; 16(9):1539-1546. [PubMed: 17899447]

44. Maddigan SL, Feeny DH, Majumdar SR, Farris KB, Johnson JA. Health Utilities Index mark 3 demonstrated construct validity in a population-based sample with type 2 diabetes. J Clin Epidemiol. 2006; 59(5):472-477. [PubMed: 16632135]

45. Maddigan SL, Feeny DH, Majumdar SR, Farris KB, Johnson JA. Understanding the determinants of health for people with type 2 diabetes. Am J Public Health. 2006; 96(9):1649-1655. [PubMed: 16873750]

46. Orpana HM, Ross N, Feeny D, McFarland B, Bernier J, Kaplan M. The natural history of healthrelated quality of life: a 10-year cohort study. Health Reports. 2009; 20(1):1-7.

47. Asakawa K, Feeny D, Senthilselvan A, Johnson JA, Rolfson D. Do the determinants of health differ between people living in the community and in institutions? Soc Sci Med. 2009; 69(3):345-353. [PubMed: 19527920]

48. Garster NC, Palta M, Sweitzer NK, Kaplan RM, Fryback DG. Measuring health-related quality of life in population-based studies of coronary heart disease: comparing six generic indexes and a disease-specific proxy score. Qual Life Res. 2009; 18(9):1239-1247. [PubMed: 19760103] 
49. Feeny DH, Furlong W, Torrance GW, Goldsmith CH, Zhu Z, DePauw S, et al. Multi-attribute and single-attribute utility functions for the health utilities index mark 3 system. Med Care. 2002; 40(2): 113-128. [PubMed: 11802084]

50. Drummond M. Introducing economic and quality of life measurements into clinical studies. Annals of Medicine. 2001; 33(5):344-349. [PubMed: 11491193]

51. Grootendorst P, Feeny D, Furlong W. Health Utilities Index Mark 3: evidence of construct validity for stroke and arthritis in a population health survey. Med Care. 2000; 38(3):290-299. [PubMed: 10718354]

52. Bernier J, Feng Y, Asakawa K. Using Multilevel Growth Model for Assessing the Variation of HUI3 Trajectories. Health Reports. 2011 in press.

53. Maddigan SL, Feeny DH, Johnson JA. Health-related quality of life deficits associated with diabetes and comorbidities in a Canadian National Population Health Survey. Quality of Life Research. 2005; 14(5):1311-1320. [PubMed: 16047506]

54. Bowker SL, Pohar SL, Johnson JA. A cross-sectional study of health-related quality of life deficits in individuals with comorbid diabetes and cancer. Health Qual Life Outcomes. 2006:4-17. [PubMed: 16423298]

55. Welch KC, Scharf SM. Construct validity for the Health Utilities Index in a sleep center. Sleep Breath. 2007; 11(4):295-303. [PubMed: 17457630]

56. Zajacova A, Dowd JB, Burgard SA. Overweight adults may have the lowest mortality--do they have the best health? Am J Epidemiol. 2011; 173(4):430-437. [PubMed: 21228416]

57. Visser M, Bouter LM, McQuillan GM, Wener MH, Harris TB. Elevated C-reactive protein levels in overweight and obese adults. The Journal of the American Medical Association. 1999; 282(22):21312135.

58. Puhl RM, Andreyeva T, Brownell KD. Perceptions of weight discrimination: prevalence and comparison to race and gender discrimination in America. Int J Obes (Lond). 2008; 32(6):992-1000. [PubMed: 18317471]

59. Gorber S, Shields M, Tremblay MS, McDowell I. The feasibility of establishing correction factors to adjust self-reported estimates of obesity. Health Rep. 2008; 19(3):71-82.

60. Janssen I, Shields M, Craig CL, Tremblay MS. Changes in the Obesity Phenotype Within Canadian Children and Adults, 1981 to 2007-2009. Obesity (Silver Spring). 2011

61. Shields M, Tremblay MS, Laviolette M, Craig CL, Janssen IGS. Fitness of Canadian adults: Results from the 2007-2007 Canadian Health Measures Survey. Health Rep. 2010; 21(1):7-20. [PubMed: 20426223]

62. Swain L, Catlin G, Beaudet MP. The National Population Health Survey--its longitudinal nature. Health Rep. 1999; 10(4):69-82. [PubMed: 10607414]

63. Moorehead MK, rdelt-Gattinger E, Lechner H, Oria HE. The validation of the Moorehead-Ardelt Quality of Life Questionnaire II. Obesity Surgery. 2003; 13(5):684-692. [PubMed: 14627461]

64. Kolotkin RL, Head S, Hamilton M, Tse CK. Assessing Impact of Weight on Quality of Life. Obesity Research. 1995; 3(1):49-56. [PubMed: 7712359]

\section{Appendix}

As noted in the main text of the paper, overall HUI3 scores were highly skewed and were transformed using the arcsine transformation to achieve normally distributed residuals. The methods are explained in detail in Bernier et al. [49]. The formula used to adjust HUI3 values is given below:

$$
H U I 3=\left[\sin a r c s i n H U I 3_{a d j}+1 \times\left(\frac{1.36}{2}\right)\right]-0.36
$$


Due to this adjustment and transformation, coefficients from growth curve models cannot be interpreted directly as changes in HUI3. Therefore, it was necessary to back-transform predicted values to the original metric prior to graphing the results.

$$
\arcsin H U I 3_{a d j}=\arcsin \left[2\left(\frac{H U I 3+0.36}{1.36}\right)-1\right]
$$



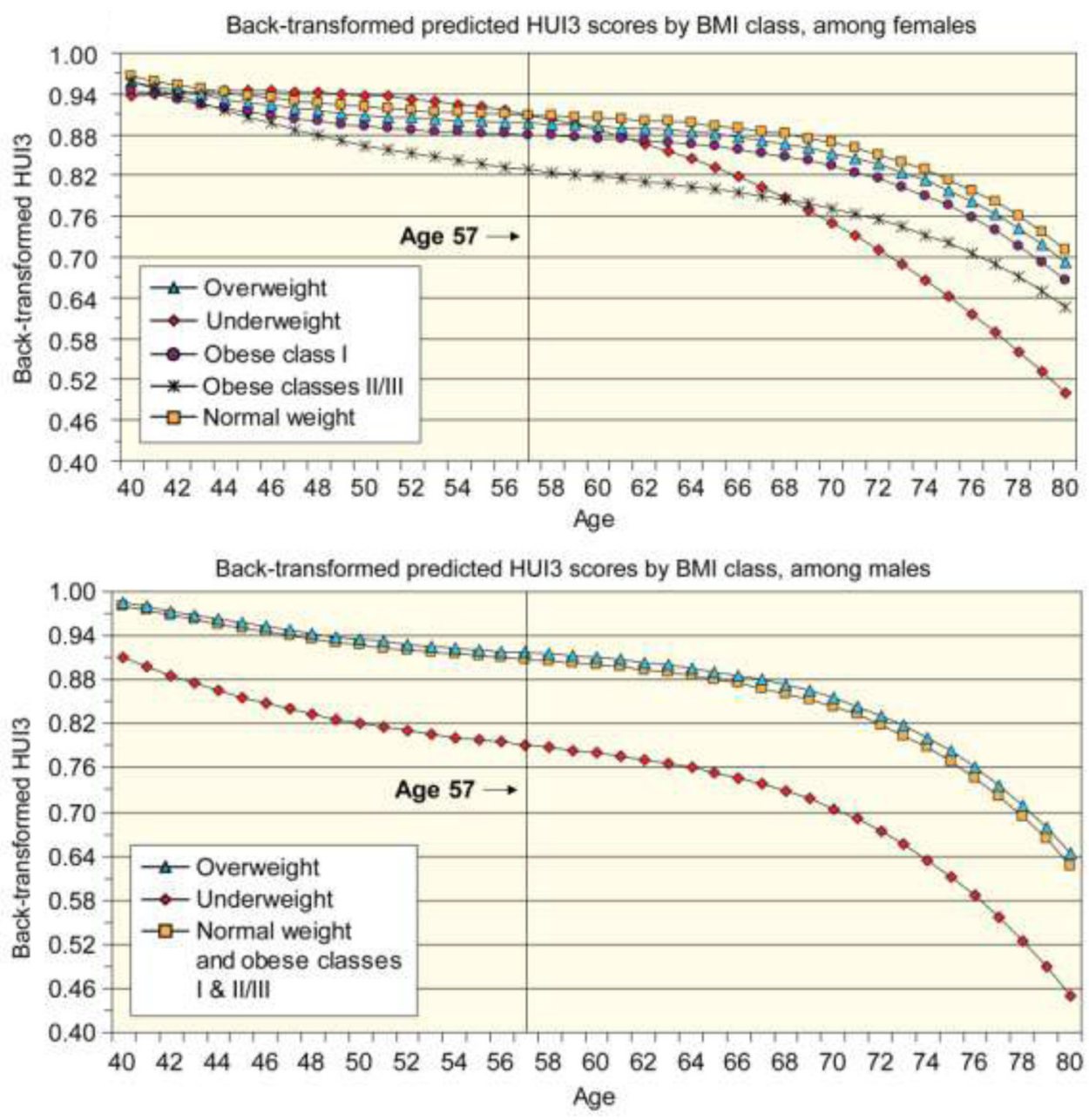

Figure 1. 
Difference in back-transformed predicted scores from normal weight by BMI category, among females

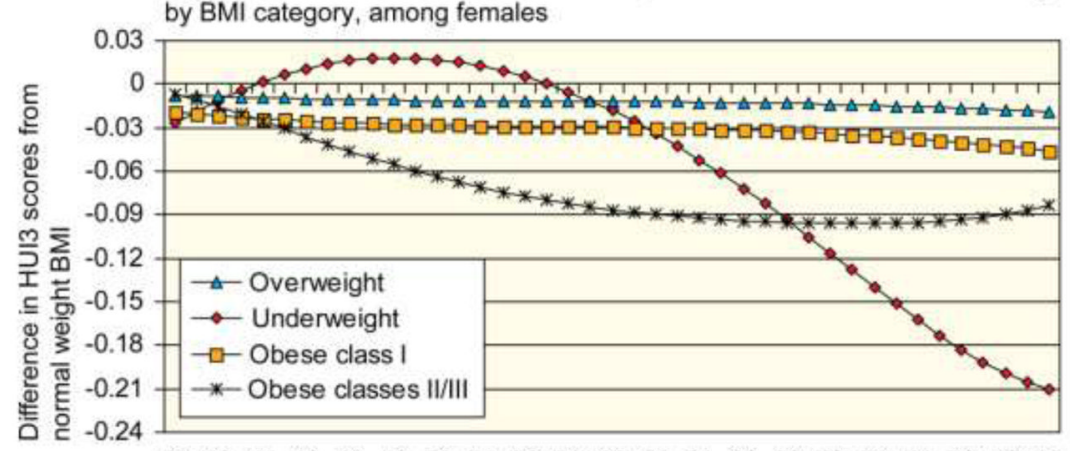

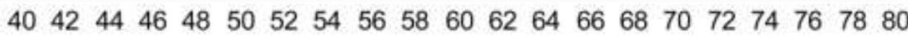

Age

Difference in back-transformed predicted scores from normal weight by BMI category, among males

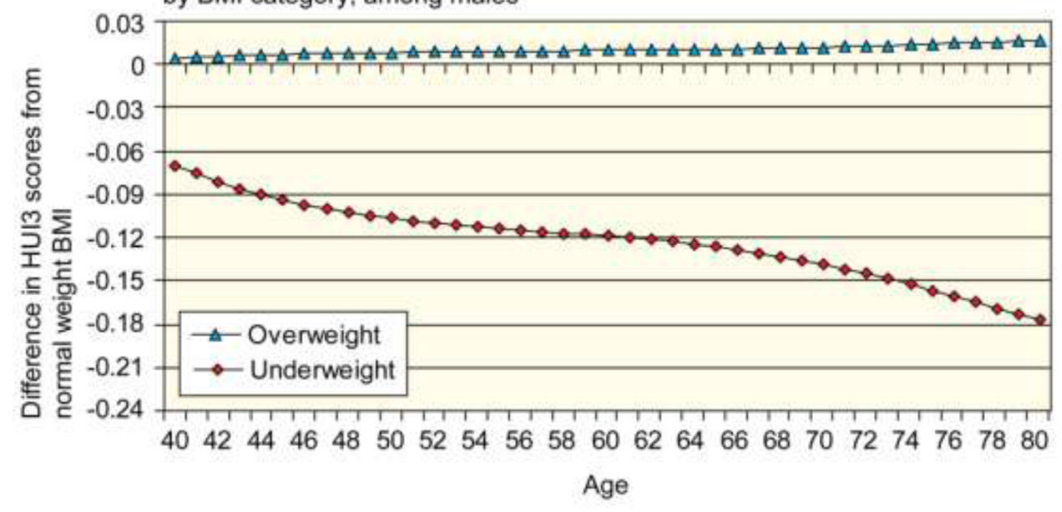

Figure 2. 
Table 1

Descriptive characteristics (\%) of the sample and comparison of male and female sample differences

\begin{tabular}{|c|c|c|c|}
\hline & Males $(n=3559)$ & Females $(n=4430)$ & \\
\hline \multicolumn{4}{|l|}{ During follow-up (1998/99 to 2006/07) } \\
\hline Institutionalized & 2.07 & 4.66 & $p<0.0001$ \\
\hline Deceased & 15.59 & 12.55 & $p=0.0006$ \\
\hline \multicolumn{4}{|l|}{ Age (1998/99) } \\
\hline $40-49$ & 36.85 & 34.12 & $\mathrm{p}=0.0054$ \\
\hline $50-59$ & 27.80 & 23.11 & $\mathrm{p}<0.0001$ \\
\hline $60-69$ & 17.37 & 19.54 & $\mathrm{p}=0.042$ \\
\hline $70-79$ & 12.79 & 15.68 & $\mathrm{p}<0.0001$ \\
\hline $80-89$ & 4.50 & 6.38 & $\mathrm{p}=0.0002$ \\
\hline $90+$ & 0.69 & 1.16 & $\mathrm{p}<0.13$ \\
\hline \multicolumn{4}{|l|}{ Marital status (1998/99) } \\
\hline Married, including common-law or living with a partner & 79.83 & 63.96 & $p<0.0001$ \\
\hline Single, never married & 6.46 & 6.50 & $p=0.95$ \\
\hline Divorced, separated or widowed & 13.72 & 29.54 & $p<0.0001$ \\
\hline \multicolumn{4}{|l|}{ Household income (1998/99) } \\
\hline Less than $\$ 15,000$ & 7.82 & 15.42 & $p<0.0001$ \\
\hline$\$ 15,000-\$ 29,999$ & 19.27 & 22.37 & $p=0.007$ \\
\hline$\$ 30,000-\$ 59,999$ & 35.44 & 34.10 & $p=0.35$ \\
\hline$\$ 60,000$ and over & 37.47 & 28.10 & $p<0.0001$ \\
\hline \multicolumn{4}{|l|}{ Educational attainment (1998/99) } \\
\hline Less than high school & 28.42 & 30.29 & $p=0.15$ \\
\hline High school graduate & 12.73 & 16.55 & $p=0.0005$ \\
\hline Some post secondary graduate training & 23.60 & 23.88 & $p=0.83$ \\
\hline Post-secondary graduate & 35.24 & 29.27 & $p<0.0001$ \\
\hline \multicolumn{4}{|l|}{ Body mass index category (1996/97) } \\
\hline Underweight & 0.76 & 2.28 & $p<0.0001$ \\
\hline Normal weight & 33.46 & 49.14 & $p<0.0001$ \\
\hline Overweight & 50.29 & 33.07 & $p<0.0001$ \\
\hline Obese class I & 12.84 & 11.74 & $p=0.27$ \\
\hline Obese classes II \& III & 2.66 & 3.77 & $p=0.03$ \\
\hline
\end{tabular}

Note: the p-values in the extreme right-hand column refer to comparisons across the row, that is whether the percent of males and females is statistically significantly different or not. 


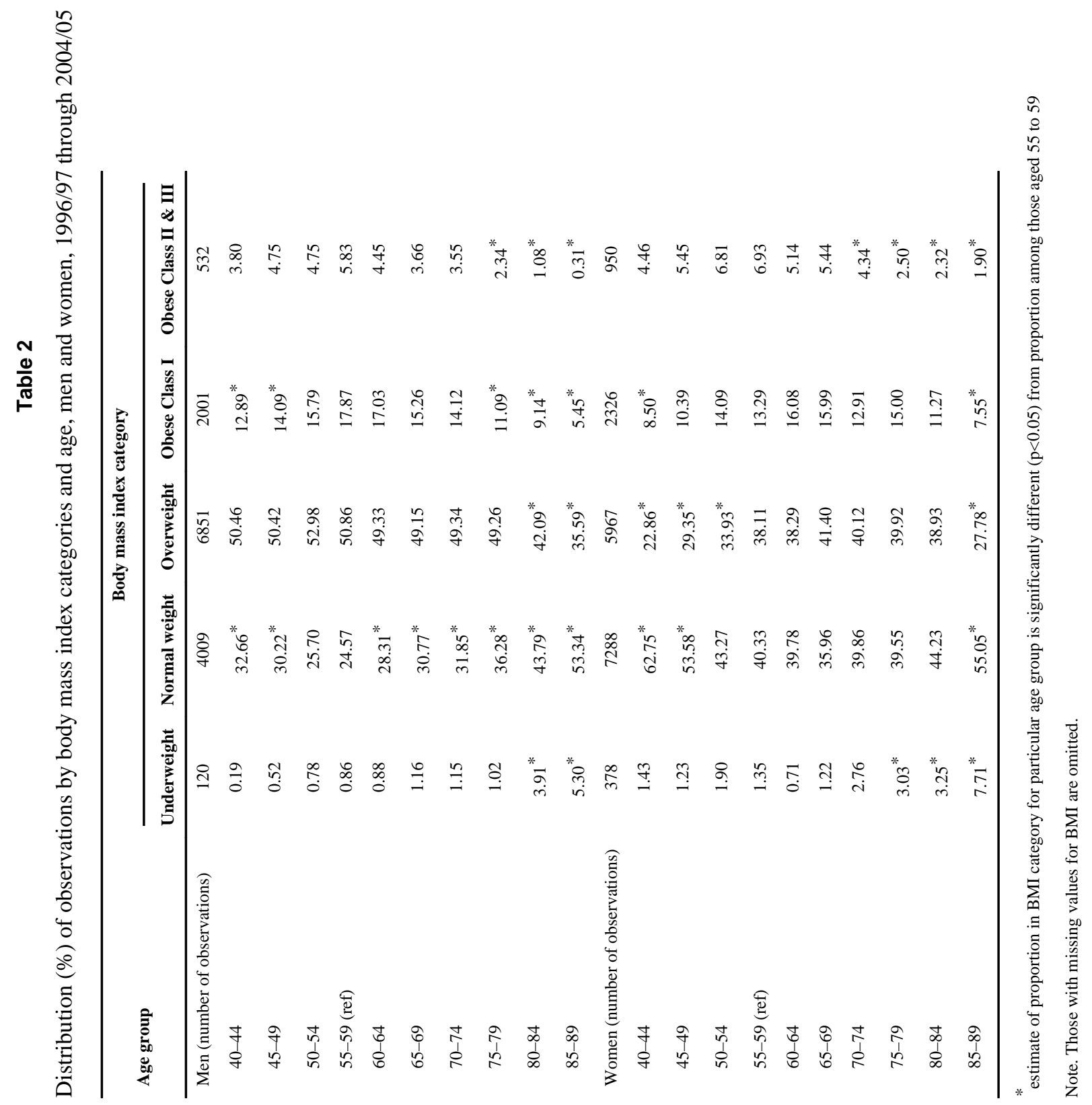


Table 3

Beta coefficients from growth curve model for men: Outcome is adjusted-transformed HUI (14,329 observations)

\begin{tabular}{|c|c|c|c|c|}
\hline & Model A: Effects of age & $\begin{array}{c}\text { Model B: Effects of BMI on } \\
\text { intercept }\end{array}$ & $\begin{array}{l}\text { Model C: Effects of BMI on rate } \\
\text { of change }\end{array}$ & Model D: Final model \\
\hline \multicolumn{5}{|l|}{ Fixed Effects } \\
\hline \multicolumn{5}{|l|}{ Baseline } \\
\hline Intercept & $1.0491^{* * *}$ & $1.0367^{* * *}$ & $1.0353^{* * *}$ & $1.0427^{* * *}$ \\
\hline Underweight & & $-0.2731^{* * *}$ & $-0.2291^{* *}$ & $-0.2766^{* * *}$ \\
\hline Overweight & & $0.0341^{* *}$ & $0.0336^{* *}$ & $0.0279^{* *}$ \\
\hline Obese class I & & 0.0187 & 0.0181 & \\
\hline Obese class II/III & & -0.0069 & -0.0056 & \\
\hline \multicolumn{5}{|l|}{ Rate of change } \\
\hline Linear & $-0.0067^{* * *}$ & $-0.0069^{* * *}$ & $-0.0078^{* * *}$ & $-0.0069^{* * *}$ \\
\hline Interaction: & & & -0.0050 & \\
\hline \multicolumn{5}{|l|}{ Underweight } \\
\hline Interaction: & & & 0.0009 & \\
\hline \multicolumn{5}{|l|}{ Overweight } \\
\hline Interaction: & & & 0.0017 & \\
\hline \multicolumn{5}{|l|}{ Obese class I } \\
\hline Interaction: & & & 0.0023 & \\
\hline \multicolumn{5}{|l|}{ Obese class II/III } \\
\hline Quadratic & 0.000013 & 0.000013 & 0.000015 & 0.000009 \\
\hline Cubic & $-0.000036^{* * *}$ & $-0.000034^{* * *}$ & $-0.000033^{* * *}$ & $-0.000034^{* * *}$ \\
\hline -2 Log Likelihood & $17,961.93$ & $17,879.59$ & $17,868.75$ & $17,881.67$ \\
\hline
\end{tabular}

Note. Indicators of missing body mass index values were included in models but are not shown in the table.

$$
\text { * } \mathrm{p}<0.05 \text {; }
$$$$
\text { ** }<<0.01 \text {; }
$$$$
* * * \text { p }<0.001
$$ 
Table 4

Beta coefficients from growth curve model for women: Outcome is adjusted- transformed HUI (18,316 observations)

\begin{tabular}{|c|c|c|c|c|}
\hline & Model A: Effects of age & $\begin{array}{c}\text { Model B: Effects of BMI on } \\
\text { intercept }\end{array}$ & $\begin{array}{l}\text { Model C: Effects of BMI on rate } \\
\text { of change }\end{array}$ & Model D: Final model \\
\hline \multicolumn{5}{|l|}{ Fixed Effects } \\
\hline \multicolumn{5}{|l|}{ Baseline } \\
\hline Intercept & $1.0116^{* * *}$ & $1.0574^{* * *}$ & $1.0484^{* * *}$ & $1.0462^{* * *}$ \\
\hline Underweight & & $-0.1389^{* * *}$ & -0.0071 & \\
\hline Overweight & & $-0.0332^{* *}$ & $-0.0393^{* *}$ & $-0.0341^{* * *}$ \\
\hline Obese class I & & $-0.0801^{* * *}$ & $-0.0804^{* * *}$ & $-0.0803^{* * *}$ \\
\hline Obese class II/III & & $-0.1748^{* * *}$ & $-0.1939^{* * *}$ & $-0.2018^{* * *}$ \\
\hline \multicolumn{5}{|l|}{ Rate of change } \\
\hline Linear & $-0.0044^{* * *}$ & $-0.0049^{* * *}$ & $-0.0034^{* * *}$ & $-0.0035^{* * *}$ \\
\hline Interaction: & & & $-0.0153^{* * *}$ & $-0.0152^{* * *}$ \\
\hline \multicolumn{5}{|l|}{ Underweight } \\
\hline Interaction: & & & 0.00052 & \\
\hline \multicolumn{5}{|l|}{ Overweight } \\
\hline Interaction: & & & 0.00058 & \\
\hline \multicolumn{5}{|l|}{ Obese class I } \\
\hline Interaction: & & & $-0.0061^{*}$ & $-0.0048^{*}$ \\
\hline \multicolumn{5}{|l|}{ Obese class II/III } \\
\hline Quadratic & 0.000034 & 0.000003 & 0.0001 & 0.000085 \\
\hline Interaction: & & & $-0.0007^{*}$ & $-0.0007^{* * *}$ \\
\hline \multicolumn{5}{|l|}{ Underweight } \\
\hline Interaction: & & & -0.00005 & \\
\hline \multicolumn{5}{|l|}{ Overweight } \\
\hline Interaction: & & & -0.00007 & \\
\hline \multicolumn{5}{|l|}{ Obese class I } \\
\hline Interaction: & & & 0.0001 & $0.0003^{*}$ \\
\hline \multicolumn{5}{|l|}{ Obese class II/III } \\
\hline Cubic & $-0.000029^{* * *}$ & $-0.000026^{* * *}$ & $-0.000031^{* * *}$ & $-0.000029^{* * *}$ \\
\hline Interaction: & & & $0.00003^{* *}$ & $0.00003^{* * *}$ \\
\hline \multicolumn{5}{|l|}{ Underweight } \\
\hline Interaction: & & & 0.000005 & \\
\hline \multicolumn{5}{|l|}{ Overweight } \\
\hline Interaction: & & & 0.000003 & \\
\hline \multicolumn{5}{|l|}{ Obese class I } \\
\hline Interaction: & & & 0.00001 & \\
\hline \multicolumn{5}{|l|}{ Obese class II/III } \\
\hline -2 Log Likelihood & $22,424.90$ & $22,170.71$ & $22,020.84$ & $22,032.52$ \\
\hline
\end{tabular}

Qual Life Res. Author manuscript; available in PMC 2013 June 01. 
Note. Indicators of missing body mass index values were included in models but are not shown in the table.

* $<<0.05$;

** $\mathrm{p}<0.01$;

$\mathrm{p}<0.001$ 